\title{
How does hair growth change with blood group?
}

\begin{abstract}
The main objective of present study was to relate the hair growth with the blood grouping. 174 subjects participated in this study at Bahauddin Zakariya University, Multan, Pakistan. 3 blood drops were taken on a glass slide with some distance between them. A drop of anti- A serum was put on first spot, anti-B serum was put on second spot and anti-D serum was put on third spot. Agglutination in blood occurred so blood group was confirmed by observing agglutination in respective blood drop. Humans have 4 major blood groups. For example A blood group, B blood group, AB blood group and $\mathrm{O}$ blood group. Parents transfer the genes to their children which decide the blood group. Each parent can donate one allele to child. Blood groups are further characterized by presence or absence of RhD antigen. Red blood cells have this antigen on their surface. Blood group is positive if RBCs have this antigen and blood group is negative if RBCs do not have this antigen. In this way, total 8 blood groups are present.
\end{abstract}

Keywords: hair growth, antigen, antibodies, blood groups, antisera, blood types, $\mathrm{RhD}$ antigen, red blood cells, anti-B antibodies, behavior

\section{Introduction}

Blood group is actually classification of blood types that is based on presence of absence of antigens or antibodies. Humans have 4 major blood groups. For example A blood group, B blood group, AB blood group and $\mathrm{O}$ blood group. Parents transfer the genes to their children which decide the blood group. Each parent can donate one allele to child. Child can also have different blood group than parents in case when both parents have B blood group then they can produce the child having either $\mathrm{B}$ or $\mathrm{O}$ blood group. Other condition is when one parent has $\mathrm{A}$ and other has $\mathrm{AB}$ blood group then they can produce the child having $\mathrm{A}, \mathrm{B}$ or $\mathrm{AB}$ blood group. Antigens ' $\mathrm{A}$ ' and anti-B antibodies are present in A blood group. Antigens ' $\mathrm{B}$ ' and anti-A antibodies are present in A blood group. 'A' and 'B' antigens are present in AB blood group but it has no antibodies. No antigens are present in $\mathrm{O}$ blood group but has both anti-A and anti-B antibodies. $\mathrm{O}$ is common among all blood groups. Receiving wrong blood group from donor can be life threatening. ${ }^{.}$Blood groups are further characterized by presence or absence of $\mathrm{RhD}$ antigen. Red blood cells have this antigen on their surface. Blood group is positive if RBCs have this antigen and blood group is negative if RBCs do not have this antigen. In this way, total 8 blood groups are present. These are A+ blood group, A- blood group, $\mathrm{B}+$ blood group, $\mathrm{B}$ - blood group, $\mathrm{AB}+$ blood group, $\mathrm{AB}$ - blood group, $\mathrm{O}+$ blood group and $\mathrm{O}-$ blood group. From these, O- can be given to anyone when required blood group is not immediately available. ${ }^{2}$ Hair can grow with different rates at different places of head. Follicles of hair do not depend on each other. They behave independently. For example in one case, when a person's hair start to fall then he may lose all hair simultaneously. In other case the person's hair may start to appear gray. The position of follicles actually determine their behavior. Some outer factors also affect their behavior. Average rate of growth of hair is 1.5 inches in one month. Male's hair grow faster than female because of testosterone. Hair growth also depends on age for example in old age follicles stop growing that is why hair becomes thin. The hair growth completes in 3 cycles. When cycle is complete then it stops and a new strand of hair begins to form. This cycle completes in different time for different people that is why they have different hair growth rate. Different hair colors and follicle shapes also affect the timing of cycle thus People do not have same rates for growth of hair.
Volume 3 Issue 2 - 2019

\author{
Muhammad Imran Qadir, Arzoo Ishaq \\ Institute of Molecular Biology and Biotechnology, Bahauddin \\ Zakariya University, Multan, Pakistan
}

Correspondence: Arzoo Ishaq, Institute of Molecular Biology and Biotechnology, Bahauddin Zakariya University, Multan, Pakistan,Tel 030364I55I5, Email arzoosamejaa@gmail.com

Received: January 21, 2019 | Published: March 28, 2019

\section{Materials and methods}

Total 174 subjects participated in this recent study. This study was performed at Bahauddin Zakariya University Multan, Pakistan.

\section{Blood grouping method}

Firstly, a needle was pricked in vein and some blood was taken out of it. Then 3 blood drops were transferred on a glass slide with some distance between them. Then antisera A, B and D were taken. A drop of anti- A was put on first spot, anti-B was put on second spot and anti-D was put on third spot. After mixing the antisera with blood drops, a reaction occurred. Agglutination in blood occurred so blood group was confirmed by observing agglutination in respective blood drop.

\section{Project designing}

The topic of project was hair growth. 174 subjects were asked about their blood group and then asked whether their hair growth is fast or slow. After this, the information was put in data form.

\section{Statistical analysis}

Statistical analysis were performed by using MS excel.

\section{Results}

How does blood group change with blood group is shown in Table 1. $10.91 \%$ subjects with blood group $\mathrm{A}+$ had fast hair growth and $6.31 \%$ had slow hair growth. $1.41 \%$ subjects with blood group A- had fastest hair growth and $0 \%$ had slow hair growth. $16.66 \%$ subjects with blood group $\mathrm{B}+$ had fast hair growth and $17.81 \%$ had slow hair growth. $1.71 \%$ subjects with B- blood group had fast hair growth and $1.41 \%$ had slow hair growth. $1.41 \%$ subjects with blood group $\mathrm{AB}+$ had fast hair growth and $3.44 \%$ has slow hair growth. $0.57 \%$ subjects with blood group $\mathrm{AB}$ - had fast hair growth and $0 \%$ has slow hair growth. $17.23 \%$ subjects with blood group $\mathrm{O}+$ had fast hair growth and $14.36 \%$ had slow hair growth. $2.87 \%$ subjects with blood group O- had fast hair growth and $2.87 \%$ has slow hair growth. 
Table I How does hair growth change with blood groups

\begin{tabular}{|c|c|c|c|c|c|c|}
\hline Blood group & Male & Female & Total & Male & Female & Total \\
\hline & (Yes) \% & (Yes) \% & (Yes) \% & (No) \% & (No) \% & (No) \% \\
\hline$A+$ & 5.74 & 5.17 & 10.91 & 1.14 & 5.17 & 6.31 \\
\hline A- & 0.57 & 0.57 & I.14 & 0 & 0 & 0 \\
\hline $\mathrm{B}+$ & 2.87 & 13.79 & 16.66 & 2.87 & 14.94 & I7.8| \\
\hline B- & 0.57 & I.14 & 1.71 & 0.57 & 0.57 & 1.14 \\
\hline$A B+$ & 1.14 & 1.72 & 2.86 & 0.57 & 2.87 & 3.44 \\
\hline$A B-$ & 0 & 0.57 & 0.57 & 0 & 0 & 0 \\
\hline $\mathrm{O}+$ & 8.04 & 9.19 & 17.23 & 1.72 & 12.64 & 14.36 \\
\hline O- & 0 & 2.87 & 2.87 & 0 & 2.87 & 2.87 \\
\hline
\end{tabular}

\section{Discussion}

Questionnaire based study has given an important advancement in recent researches. ${ }^{3-10}$ A recent study on Alopecia by Chandigarh-based Plastic Surgeon Dr. Tejinder Bhatti says that blood groups play a major role in determining hair growth. For example people having $\mathrm{A}+$ blood group cannot absorb B vitamins in their blood and that is why thickness of their hair is low. Therefore people having ' $A$ ' positive blood group have more chances of baldness. This study was initiated in 2007 and completed in December 2012. ${ }^{11}$

\section{Conclusion}

It was concluded from recent study that maximum hair growth occurs in $\mathrm{O}+$ blood group and minimum hair growth occurs in $\mathrm{B}+$ blood group.

\section{Acknowledgments}

None.

\section{Conflicts of interest}

The author declares there is no conflict of interest.

\section{References}

1. Qadir MI, Malik SA. Comparison of alterations in red blood cell count and alterations in hemoglobin concentration in patients suffering from rectal carcinoma undergoing 5-fluorouracil and folic acid therapy. Pharmacologyonline. 2010;3:240-243.
2. Qadir MI, Noor A. Anemias. Rare \& Uncommon Diseases. Cambridge Scholars Publishing. Newcastle, England. 2018;ISBN: 978-1-52751807-0.

3. Qadir MI, Javid A. Awareness about Crohn's Disease in biotechnology students. Glo Adv Res J Med Medical Sci. 2018;7(3):062-064.

4. Qadir MI, Saleem A. Awareness about ischemic heart disease in university biotechnology students. Glo Adv Res J Med Medical Sci. 2018;7(3):059-061.

5. Qadir MI, Ishfaq S. Awareness about hypertension in biology students. Int J Mod Pharma Res. 2018;7(2):08-10.

6. Qadir MI, Mehwish. Awareness about psoriasis disease. Int J Mod Pharma Res. 2018;7(2):17-18.

7. Qadir MI, Shahzad R. Awareness about obesity in postgraduate students of biotechnology. Int J Mod Pharma Res. 2018;7(2):14-16.

8. Qadir MI, Rizvi M. Awareness about thalassemia in post graduate students. MOJ Lymphology \& Phlebology. 2018;2(1):14-16.

9. Qadir MI, Ghalia BA. Awareness survey about colorectal cancer in students of M. Phil Biotechnology at Bahauddin Zakariya University, Multan, Pakistan. Nov Appro in Can Study. 2018;1(3):ACS.000514.2018.

10. Qadir MI, Saba G. Awareness about intestinal cancer in university student. Nov Appro in Can Study. 2018;1(3):NACS.000515.2018.

11. Tejinder Bhatti. A factor leading to baldness. THE TIMES OF INDIA. Chandigarh. 2018. 